\title{
INTERACTIVE COMPUTER SIMULATION AS A RESPONSE TO CONTEMPORARY PROBLEMS OF TECHNICAL EDUCATION
}

\author{
Tomasz Prauzner \\ Institute of Technological and Safety Education, \\ Jan Długosz University, Częstochowa, Poland
}

\begin{abstract}
The theory of teaching, commonly referred to as didactics, is gaining increasing recognition in the work of a teacher immersed in the present-day reality of education. It appears right to assume that familiarity with the changing world should inspire innovativeness aimed to eliminate unnecessary or inadequate phenomena. For this reason, it is advisable to treat didactics as a theoretical discipline with practical implications for teachers, especially in the process of transforming and perfecting the educational system to make it meet the real social and economic challenges. The paper presents empirical studies conducted in the period 2010-2015 among full-time and weekend students of Safety Engineering at Jan Dlugosz University in Czestochowa, Poland. The studies were aimed to test the hypothesis that using deterministic computer simulations in the didactic process fosters learning effectiveness in the field of technological education as compared to traditional methods applied in a laboratory. The investigation employed extended methodology including verifying detailed hypotheses by means of empirical studies proved to be significant by the $\chi 2$ (chi-squared) test. It was also situated within the general theory of education, additionally addressing the postulates of constructivist and cognitivist paradigms of learning.
\end{abstract}

Keywords: interactive computer simulation, media education, didactics, information society

\section{Introduction}

Information technology currently plays an important role in shaping attitudes towards new challenges in post-industrial society. This is especially true about education, with IT being the leading factor in setting new directions for its development and offering new possibilities of solving problems related to instruction in new disciplines or vocations. Education, especially of vocational kind, has to comply with new curricula and be supported by technology (Freedman, 2011; Gerhard, 2011). The discussion and results of research presented in this paper are aimed to demonstrate that the application of IT in teaching is a complex issue, considering the challenges that schooling has to meet nowadays. The main research problem which can be generally described as effectiveness of teaching with the use of modern technologies will be addressed 
Tomasz Prauzner. Interactive Computer Simulation as a Response to Contemporary Problems of Technical Education

by analysing the teaching of technical subjects in tertiary education at Jan Dlugosz University in Częstochowa.

\section{Discussion}

As previous research by the author has demonstrated, in the current situation of the technical schools, the most effective method for implementing a constructivist-connectivist education model is auxiliary teaching employing modern information technology (Prauzner, 2013). In the second half of the 19th century and the first half of the 20th century, John Dewey and Jean Piaget were the first to observe that theoretical knowledge must be combined with its practical applications. Piaget's fundamental thesis is that thinking does not involve static images of reality but internalised action schemas so that a learner does not merely memorise images but mental operations accompanying actions. According to constructivism, getting ready for creative work requires practising many skills which are neglected in traditional education. These skills include constructing new knowledge on the basis of old knowledge by shaping imagination, implementing new ideas, taking decisions, creating models and conceptions of reality, searching for information and using it, and others. Creative thinking and active group collaboration is one the targets to be practised by using simulation programmes for learning and implementing technical knowledge (Prauzner, 2015b). Connectivism, on the other hand, underscores the importance of learning to think, as opposed to learning knowledge. Following these postulates, research was conducted to verify the hypothesis that modern computer programmes can foster a student's cognitive development (Noga, Piaskowska-Silarska, Depešová, Pytel, Migo, 2014). The innovative character of the author's research involved the following:

- Due to a dynamic development of new information technologies present in the education of young generations, the topic is in the centre of interest of psychologists and teachers because of its relevance for didactics and education (Prensky, 2011). From this viewpoint, the topic is current as new variables appear and have to be accounted for.

- Technical education of all levels is considered attractive, prestigious and useful by young people in light of the job market demands. The young generation finds the technical education programmes offered by universities interesting, at the same time providing good employment opportunities (Noga, 2009).

- Considering current global problems related to environmental issues or threat of terrorist attacks, technical and engineering specialist 
- education, requires innovative methods and teaching aids employing modern technology;

- A possible way to obtain innovative programming solutions is by the use of Deterministic Computer Simulation (DCS) models offering virtual environments, based on mathematical algorithms and approved by scientists as providing a full-fledged environment for verifying results obtained in previous research;

- Currently used interactive DCS programmes are highly specialised and use a dialogic format. They are a practical response to the connectivist and constructionist postulates:

- DCS are commonly used by security companies and services so good familiarity with them is required of engineering graduates;

- The present generation of young people is often referred to as the generation of digital natives, who shaped their identity being surrounded by information technology devices. This is another argument for applying IT in innovative educational practice;

- The most important objective of the research work is to indicate all the factors conducive to learning and hampering learning in the practice of technical education based on deterministic computer simulations.

\section{Methodology}

The study consists of two phases. The first one is a pilot study whereas the second main phase is based on the classical experimental design with some modifications (Table1)

Table 1 Classical experimental design

\begin{tabular}{|l|c|c|c|c|}
\hline Group & $\begin{array}{c}\text { Initial } \\
\text { measurement } \mathrm{P}_{\mathrm{p}}\end{array}$ & Interfering factor $\mathrm{C}_{\mathrm{z}}$ & $\begin{array}{c}\text { Final } \\
\text { measurement } \mathrm{P}_{\mathrm{k}}\end{array}$ & $\begin{array}{c}\text { Difference } \\
\mathrm{R}\end{array}$ \\
\hline Experimental & $\mathrm{P}_{\mathrm{pE}}$ & Occurs & $\mathrm{P}_{\mathrm{kE}}$ & $\mathrm{P}_{\mathrm{pE}}-\mathrm{P}_{\mathrm{kE}}=\mathrm{R}_{\mathrm{E}}$ \\
\hline Control & $\mathrm{P}_{\mathrm{pK}}$ & does not occur & $\mathrm{P}_{\mathrm{kK}}$ & $\mathrm{P}_{\mathrm{pK}}-\mathrm{P}_{\mathrm{kK}}=\mathrm{R}_{\mathrm{K}}$ \\
\hline
\end{tabular}

Before the main study started, an anonymous survey was conducted among a group of selected respondents. The survey consisted of open and closed questions about the respondent's opinion on their previous experience with simulation programmes. The results obtained will be used for constructing the experimental research by determining the significance of destructive factors (independent or random variables) characteristic of this population. Such factors can potentially have a significant influence on the how the study proceeds. 
Tomasz Prauzner. Interactive Computer Simulation as a Response to Contemporary Problems of Technical Education

\section{Stages of the study main phase}

a) Introductory phase - its aim is to indicate significant differences in initial knowledge in the groups under study with respect to factors determining effectiveness of education. The initial level of knowledge was assessed on the basis of an introductory test. The questions used in the test concerned general knowledge in the field of technology, physics, chemistry, mathematics and IT on the level of junior high and high school. The participants' knowledge was assessed by means of the standard four-grade scale ranging from fail to very good. When the differences between individuals were established, it was possible to start the next stage of the study, in which the population tested was divided into experimental and control groups. The groups with the lowest score became experimental groups and the ones with the higher score became control groups. This way of allocating individuals to groups was motivated by the fact that the effectiveness of teaching is of special importance when working with students characterised by lower levels of initial knowledge. Besides, one of the aims of applying innovative teaching methods is to equalise (as much as possible) the initial differences in knowledge and skills among students.

b) Experiment consisting in conducting laboratory classes using DCS with experimental groups, preceded by a lecture providing the necessary instructions. The tasks performed by participants included learning how to use software packages, practising the skill of model and results interpretation, and correcting errors made during the preparation of input data. Control groups worked on the same problems, but their tools were of traditional type and mostly consisted of analytic calculations, static visualisations in the form of computer presentations, calculation sheets, laboratory measurements taken in a metrological laboratory and so on.

The projects the two groups worked on included the following:

Evacuating people from closed objects. The control group used the Pauls model, a simplified Kikuja-Togawa model, the Galbreath model, the Melinek and Booth model, the Hamanowicz model and the Helbing model, whereas the experimental group used the software Pathfinder (Fig.1).

Producing magnetic and electromagnetic sensors on the basis of a design with technological specifications. The control group used analytic computations and the experimental group used the software Maxwell Ansys, Quickfield, and other (Fig.2). (Prauzner, 2014; Prauzner, 2015a)

A design of electrical alarm system. The control group used analytic computations and the experimental group used the software Multisim, 
Electronics Workbanch. (Fig.3) (Ptak \& Borowik, 2012; Ptak \& Borowik, 2014, Ptak \& Borowik, 2015; Ptak \& Prauzner, 2013; Prauzner \& Ptak, 2014)

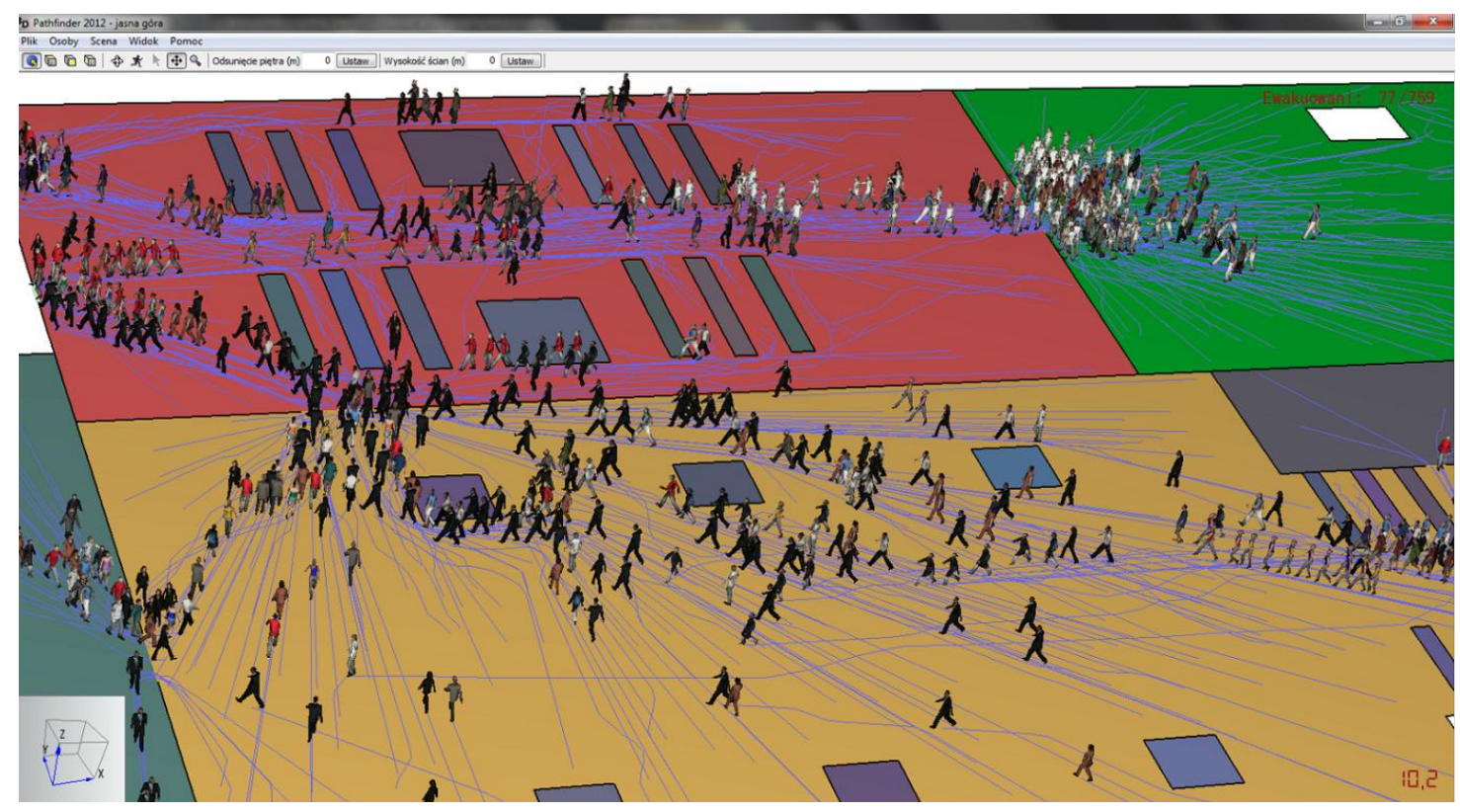

Fig. 1 Photograph presenting evacuation from the Jasna Gora Basilica

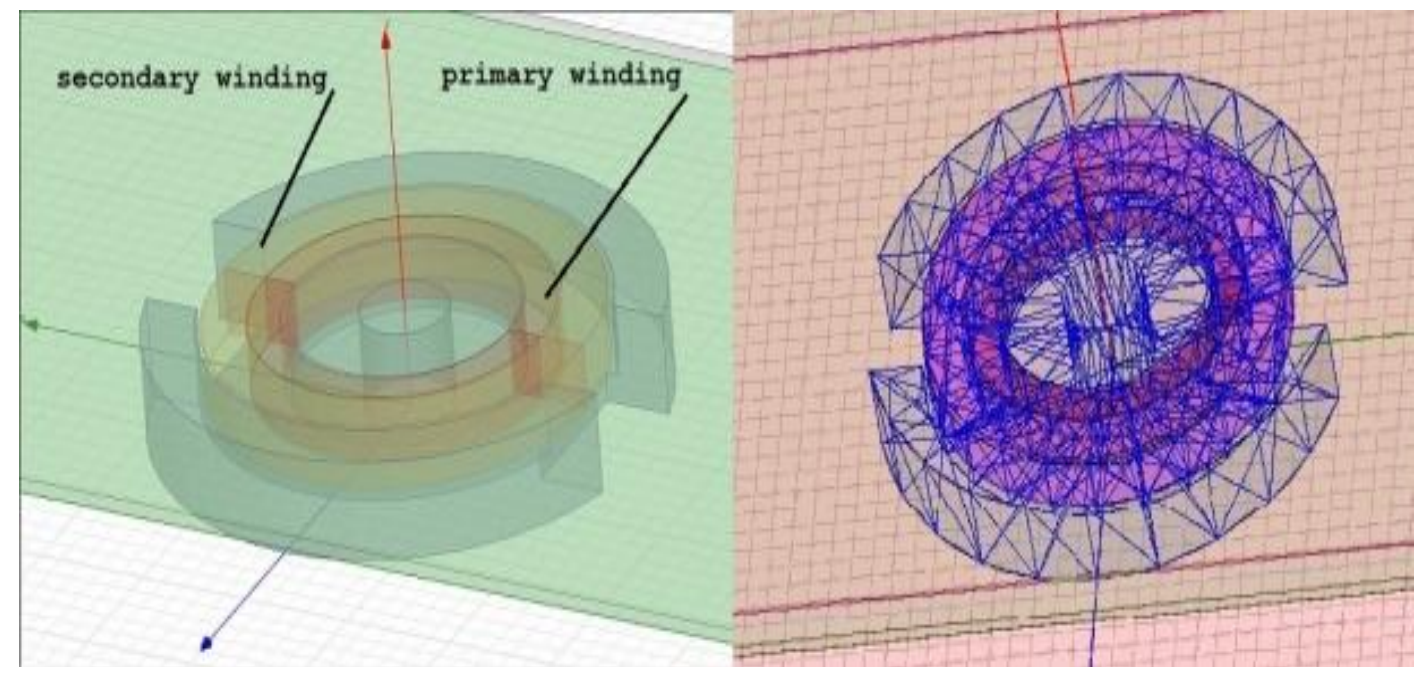

Fig. 2 Photograph presenting a model and simulation of the electromagnetic sensor in the software Ansys Maxwell 
Tomasz Prauzner. Interactive Computer Simulation as a Response to Contemporary Problems of Technical Education

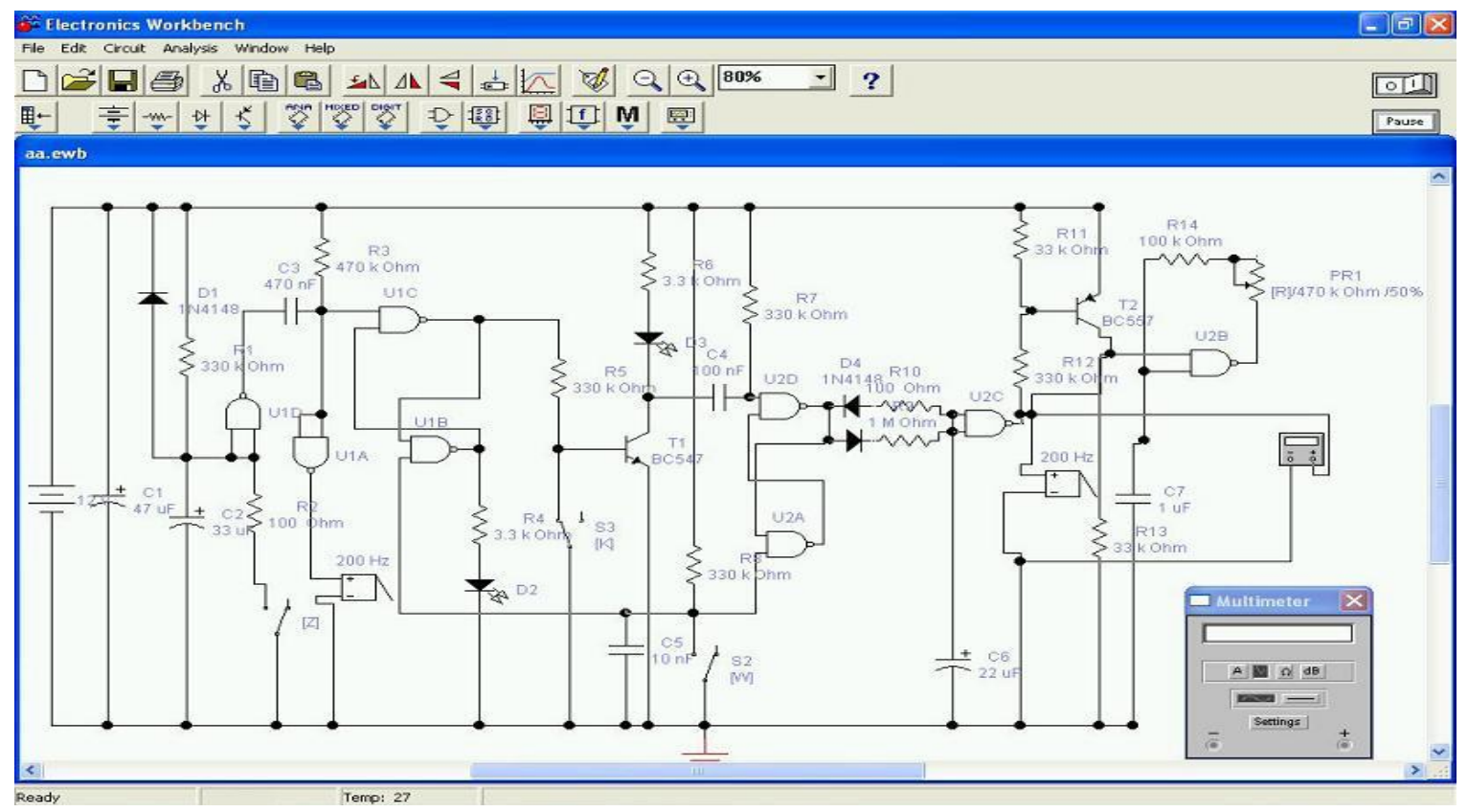

Fig. 3 Photograph presenting a model of the electronic system obtained in the software Multisim

The main research question was: Does the use of deterministic computer simulations (DCS) in technical education foster effectiveness of teaching as compared to traditional didactic methods applied in laboratory classes? If so, what is the magnitude of this effect?

The main research question implied the following detailed questions and hypotheses:

Q1.Does the use of DCS develop creativity and cognitive efficiency in technical education? If yes, what is the magnitude of this effect?

Q2. Does the use of DCS develop imagination in the field of technical education? If yes, what is the magnitude of this effect?

Q3. Does the use of DCS foster understanding of physical phenomena occurring in the technical problem under scrutiny? If yes, what is the magnitude of this effect?

Q4. Does the familiarity with DCS help in finding solutions to professional problems? If yes, what is the magnitude of this effect?

Q5. Does the use of DCS affect the amount of knowledge acquired in the field of technology? If yes, what is the magnitude of this effect?

Q6. Do deterministic computer simulations in general enhance interest in science?

Q7.Does the DCS method provide motivation for further learning? Does it make the learner active? 
Q8. Does the experience with DCS affect decisions to undergo further training in order to raise one's qualifications? If yes, what is the magnitude of this effect?

On the basis of the main research problem, the following working hypothesis was built: The use of DCS in the didactic process fosters the effectiveness of teaching in the field of technical education as compared to the traditional methods applied in a laboratory.

On the basis of the detailed research problems, detailed hypotheses were constructed, independent and dependent variables as well as indicators were defined.

\section{Results of Research}

The data obtained were analysed by means of statistical methods in order to confirm or disconfirm the effect and its magnitude of using the modern didactic methods in the experimental group. The statistical analysis was based on the non-parametric chi-square independence test (Greenwood, P.E.; Nikulin, M.S., 1996). This type of test was selected due to the sufficient number of participants, lack of necessity to investigate the type of variable distribution and the applicability of the test for examining the correlation of two qualitative variables. First, the number of participants and the grades obtained by them in both groups were compared for the particular years when the experiment was conducted. The analysis of the data collected in this way is aimed to show that two qualitative variables in a population are independent. The $\chi^{2}$ (chi-square test), developed by Karl Pearson in 1900, is a method for finding out if some data included in a contingency table provide a sufficient proof that two variables are correlated. The $\chi^{2}$ consists in comparing the observable frequencies with expected frequencies, with the null hypothesis being that there is no correlation between the two variables (Miller, R., Siegmund, D., 1982). A Microsoft Excel sheet was used for performing the calculations. The $\chi^{2}$ test was applied for the commonly accepted in statistical analyses level of $\mathrm{p}=0,05$ (i.e., the acceptable level of error is 1 error for 20 cases analysed when confirming or disconfirming the null hypothesis). To make the calculations more precise, the experimental and control groups consisting of full-time and extramural students were treated jointly. Due to the ample size of data analysed, the results obtained are presented in a compact form (Graph1). 
Tomasz Prauzner. Interactive Computer Simulation as a Response to Contemporary Problems of Technical Education

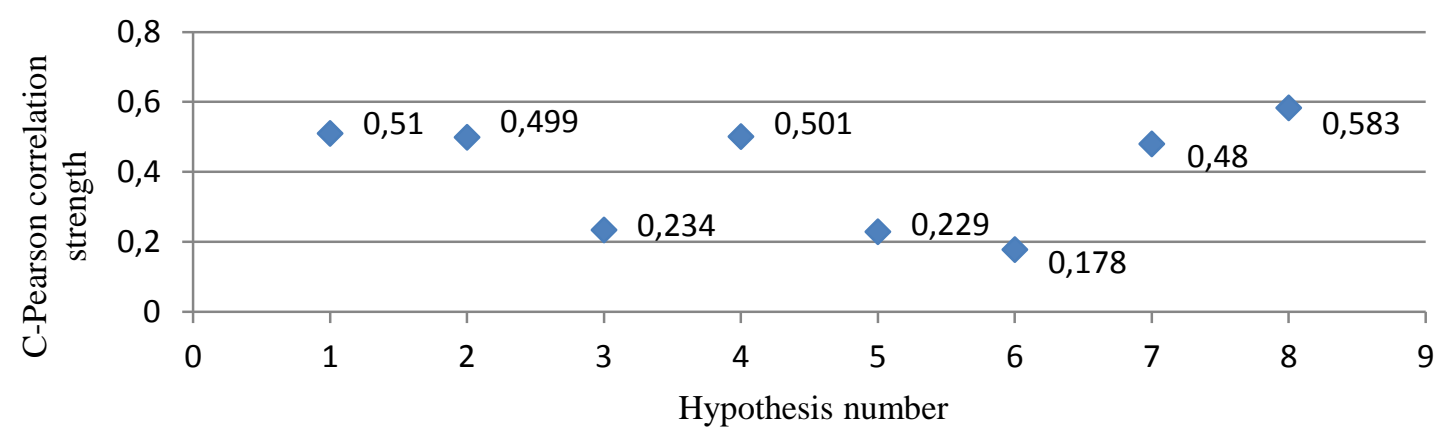

Graph 1 Graphic interpretation of the strength of connections in the respective hypotheses

\section{Conclusions}

On the basis of the data obtained it can be concluded that the variables observed in the experimental and in the control groups are tied. The particular hypotheses were verified and confirmed as true. It has to be noted, however, that the Pearson coefficient indicates a different strength of the ties between the variables. On the whole, the strength is in the range 0.178 to 0,583 , which means that the particular hypotheses form a continuum from weak to strong (according to Guilford).

Hypothesis 1 shows strong ties between the variables, thereby confirming the statement that using DCS in the didactic process fosters the development of creativity and cognitive effectiveness in forming new concepts and technological solutions, introducing innovations into existing solutions, and original thinking.

Hypothesis 2 is of moderate correlation strength. Using DCS helps develop imagination understood as being able to create correct geometrical and spatial models and to represent its dynamic, static and constructional parameters. The correlation is somewhat lower than in the previous point but it is still significant.

The C-Pearson coefficient for hypothesis 3 is much lower and so is the strength of variable correlation. Still, the hypothesis can be assumed to be true. That means that the use of DCS in experimental groups helps, albeit to a limited extent, understand physical processes occurring within the technical problem under scrutiny by enabling the interpretation of facts, theorems as well as mathematical and physical dependences on the basis of the models constructed and their simulations.

The correlation coefficient for hypothesis 4 is on the border between moderate and strong. The hypothesis being true, DCS are an excellent tool for solving professional technical problems and provide a viable alternative to traditional methods. 
Hypothesis 5 is assumed to be true as well, which proves that using DCS in the didactic process has a positive effect on the acquisition of technical knowledge. The correlation is however weak. Detailed analysis of the participants answers has led to the observation that participants from both groups had to use additional sources, such as textbooks and online resources to obtain access to knowledge necessary for solving problems. The traditional didactic method and the one employing DCS involve the same set of theorems, definitions and characteristics of physical phenomena, so getting to know them required the same amount of work. It appears that the small difference between the experimental and control group was due not so much to the differences in acquiring external knowledge associated with the content of tasks, but the very ability to use the software and learn new work methods.

Hypothesis 6 was confirmed, which suggests that the use of DCS in the didactic process enhances interest in science. The correlation coefficient being low, the impact is rather small. According to the participants, their interest in various domains of science does not depend significantly on the working methods and tools used. Individual interest in a specific domain of science is a personal trait, which affects their choice of university. The small differences between the two groups are due to interest in modern methodology as a tool for solving specific problems in science.

Hypothesis 7 was confirmed as well, indicating that the use of DCS fosters activation and motivation for further learning. The correlation is of moderate strength.

Hypothesis 8 was confirmed, indicating that the use of DCS motivates selfeducation understood as a process of obtaining knowledge, skills and practical abilities aimed to raise one's professional qualifications and competence. The correlation strength is high - the highest of all the hypotheses tested. As was observed, the innovative DCS tools motivated students to study by making the classes more attractive. The possibility to use the software to solve problems made the respondent aware that the tool is highly useful in everyday work. Since the simulation software is commonly applied by institutions and companies dealing with public safety, the ability to use such software is an essential skill for present and future employees of such institutions. It was observed that a number of extramural students enrolled in additional courses, both traditional and online, to have an opportunity to acquire and practice that skill. The courses available include those offered by MESco in Tarnowskie Góry- a representative of the Ansys Maxwell software manufacturer or STIGO offering training courses using the programmes Parhfinder and Pyrosim. 
Tomasz Prauzner. Interactive Computer Simulation as a Response to Contemporary Problems of Technical Education

\section{References}

Freedman, T. (2011). The educational technology site. Downloaded from http://www.ictineducation.org

Gerhard, P. (2011). Insight observatory for new technologies and education. Downloaded from http://www.xplora.org

Greenwood, P.E.; \& Nikulin, M.S. (1996). A guide to chi-squared testing. New York: Wiley.

Miller, R., \& Siegmund, D. (1982). Maximally selected Chi-square statistics. Biometrics. International Biometric Society

Noga, H. (2009). Sociometric methods in technological and information technology education. In: Trends in Education. Information technologies and technical education. Olomouc, Vols.1, pp.165-169

Noga, H., Piaskowska-Silarska, M., Depešová, J., Pytel, K., \& Migo P. (2014). Neuro didactic perspective of creative attitude towards education in the third millennium examination of individual cases. In: Emerging eLearning Technologies and Applications (ICETA), 2014 IEEE 12th International Conference on. pp. 355 - 360

Prauzner, T. (2013). Information Technology in Contemporary Education - Individuals' Researche. American Journal of Educational Research, 2013, Vol. 1, No. 10, online, http://www.sciepub.com

Prauzner, T., \& Ptak, P. (2014). Analiza parametrów pracy wybranych czujników pola magnetycznego. Przeglad Elektrotechniczny, R. 90 NR 12/2014, pp.273-276.

Prensky, M. (2011). Mark Prensky, Practical, Visionary. Downloaded from http://www.marcprensky.com

Ptak, P., Borowik, L. (2015). Badanie wielowarstwowych powłok ochronnych. Przeglad Elektrotechniczny, R. 91 NR 12/2015, pp.209-211.

Ptak, P., \& Borowik, L. (2012). Diagnostyka zabezpieczeń antykorozyjnych na potrzeby elektroenergetyki. Przeglad Elektrotechniczny, nr 09a, pp. 142-145.

Ptak, P., \& Borowik, L. (2014). Dokładność czujników indukcyjnych w defektoskopii warstw ochronnych urządzeń elektrycznych. Przeglad Elektrotechniczny, R. 90 NR 12/2014, pp.277-280, ISSN 0033-2097

Ptak, P., \& Prauzner, T. (2013). Badanie czujników detekcji zagrożeń w systemach alarmowych. Przeglad Elektrotechniczny, NR 10/2013, pp.274-276. ISSN 0033-2097

Prauzner, T. (2014). Effectiveness of magnetic detectors in alarm systems. Przeglad Elektrotechniczny, 90 (2014), nr.12, pp.269-272 ISSN 0033-2097

Prauzner, T. (2015a). Finite Element Method in an analysis of selected parameters of an inductive sensor for protective coatings measurements. Przeglad Elektrotechniczny, 91 (2015), nr.12, pp.205-208 ISSN 0033-2097

Prauzner, T. (2015b). Analysis of the Results of the Pedagogical Research and Eeg in the Aspect of Effective Modern Teaching Aids in the Technical Education. In: Society, Integration, Education. Proceedings of the International Scientific Conference, pp.480490 